\title{
Raz on Reasons, Reason, and Rationality: On Raz's From Normativity to Responsibility
}

\section{Ruth Chang*}

If like me you are someone who has long-admired Joseph Raz and followed his work, then reading his latest book, From Normativity to Responsibility, will be another uniquely Razian treat. There are the subtle distinctions, the complex layers of interrelated argument, and above all the frequent moments of "Aha!" when, after working through an especially intricate passage one sees that Raz has, as usual, come at an idea in an unexpected and insightful way. Over the past 40-odd years, Raz has written some of the deepest, richest, and most insightful work about law, authority, reasons, political morality, individual morality, practical reason, and value. ${ }^{1}$ From Normative to Responsibility, which offers a unified account of normativity and its relation to individual responsibility, is as deep, rich, and insightful as the rest.

The big idea behind FNR is our Being in the World. Raz wants to understand how we are in the world, that is, our place in and relation to the world. He takes as his starting point the idea that how we are in the world is a matter of our engagement with it, and our engagement is essentially normative in character. Certain features of the world make it appropriate for other features of the world to exist. We engage in the world by responding to those features, for example by having certain attitudes and performing certain actions. When our response to a feature is to bring about the features it is appropriate to bring about, we respond appropriately. In short, our being in the world is a matter of our appropriately responding to features of the world that make it appropriate for other features of the world to exist. This relation of appropriateness between some features of the world and between those features and our responses is one of normativity. In order to explain our Being in the World, then, we need to understand normativity.

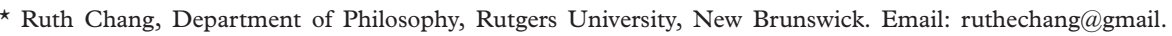
com. Thanks to David Enoch for inviting me to a conference on Raz's book and for helpful editorial comments. Special thanks to Joseph Raz for years of wonderful philosophical inspiration.

${ }^{1}$ His eleven books are as follows: The Concept of a Legal System (1970), Practical Reason and Norms (1975), The Authority of Law (1979), The Morality of Freedom (1986), Authority (1990), Ethics IN the Public Domain (1994), Engaging Reason (1999), Value, Respect and Attachment (2001), The Practice of Value (2003), Between Authority and Interpretation (2009), and From Normativity to Responsibility (2011). All page references throughout refer to From Normativity to RESPONSIBILITY unless otherwise specified.

(C) The Author 2013. Published by Oxford University Press and the Hebrew University of Jerusalem. All rights reserved. For Permissions, please email: journals.permissions@oup.com 
Since the bulk of the book concerns normativity in one way or another, that will be my focus here. I begin by describing Raz's general approach to an account of normativity and raise a worry about his focus on reasons as its "key" $(\$ 1)$. I then turn to the three central components of his view, reasons, Reason, and rationality, and explore some issues raised by his conception of each $(\mathbb{S} 2-4)$. Some of the issues will be, as it were, "in-house", since I am in broad agreement with much of what Raz says, while others will be foundational, aimed at the family of views of which his can be understood as a member. Perhaps the deepest and most controversial claim Raz makes about normativity concerns its "source", or that in virtue of which something is normative. I end with skepticism about his understanding of normative source $(\$ 5)$.

There is much in the book that I will not be discussing. These include: a defense of the claim that intentional actions are always performed under the "guise of the good"; a proposal for understanding the fundamental difference between epistemic and practical reasons (which I mention briefly below); an argument that practical reasoning is not a distinctive form of reasoning - ending in an intention-but just reasoning about practical subject matters; a case for thinking that one's ends do not provide one with a reason to pursue their means; an analysis of different kinds of conflicts of reasons; a critical discussion of aggregation and maximization; and a proposal for a novel and intriguing account of individual responsibility according to which we are responsible even if our capacities to recognize and respond to reasons malfunction. As this list helps to show, Raz's FNR is nothing short of a tour de force of major topics in the philosophy of practical reason.

\section{The "key" to normativity}

Raz's most basic claim about the nature of normativity is that reasons are the "key" to its explanation. As he writes, "the explanation of normativity is the explanation of reasons..."(5-6), and "all normative phenomena are normative in as much as, and because, they provide reasons or are partly constituted by reasons" (85). In short, if you want to understand normativity, you need to start with reasons.

Many philosophers will find the claim that the explanation of normativity is the explanation of reasons obviously true. Raz himself warns that he finds the claims he makes in the book "trivially true" while at the same recognizing that they "may, of course, be wrong" (3). Others, like myself, will find the claim that reasons are the "key" to normativity false. I believe that reasons are too thin and formal a tool for explaining normativity; values, not reasons, are its "key." 
To see why, consider the explanatory work in the domain of practical reason that reasons can do, on the one hand, and values can do, on the other. Suppose, as Raz and many others do, that reasons for action are given by natural facts, such as the fact that the medicine will cure the disease. So your reason to take the medicine is that it will cure your disease. But now ask, Why is that fact a reason to take the medicine? The normative fact that curing the disease is a reason to take the medicine is not itself a reason but a higher-order fact about your first-order reason to take the medicine. What explains this higher-order fact? Why, in particular, is the fact that it cures the disease a reason to take the medicine as opposed to, say, a reason not to take it?

"Reasons-centrists", like Raz, who think that we can explain normativity in terms of reasons, must, at some point at the end of a chain of "why" questions, end with "it's just a normative fact that $\mathrm{x}$ is a reason to $\mathrm{y}$ ". But common sense tells us that in each such case there is a further, intuitive explanation in the offing. We can explain, for example, why curing the disease is a reason to take the medicine as opposed to a reason not to take it: curing the disease is good in some way. If curing the disease were bad-if, for, example, having the disease were the only alternative to an agonizing death - then curing the disease would be a reason not to take the medicine. The point is not that only reasons-centrists must end a chain of "why" questions and "value centrists" need not; the former will end with an appeal to reasons while the latter will end with an appeal to values. The point is that explanation does not seem to end with reasons but can instead plausibly end with values.

Some philosophers think that every value claim can be translated into a corresponding reasons claim - to say that curing the disease is good is to say that there is a reason to cure the disease. Thus, if we say that "being good" explains why curing the disease is a reason to take the medicine, we are saying that "being supported by a reason" explains why curing the disease is a reason to take the medicine. But translation is not the same as explanation. Explaining the normative fact that $\mathrm{x}$ is a reason to $\mathrm{y}$ by saying that $\mathrm{x}$ is supported by reasons is not informative in the way that explaining that fact by saying that $\mathrm{x}$ is good is informative. So even if there is mutual inter-translatability among reasons- and values-talk, focusing on reasons as the key to understanding normativity cuts explanation short when there is more explanation to be had. By taking values and not reasons as the key to understanding normativity, value-centrists can, arguably, deliver a fuller, richer, and more accurate understanding of normativity. ${ }^{2}$

\footnotetext{
${ }^{2}$ Although more controversial, the same point can be made in the case of epistemic reasons. Ending a chain of explanation with "it's just a fact that the perception that it's raining is a reason to believe that it's raining" is less explanatorily satisfying than going on to say "the perception that it's raining is a reason to believe that it's raining because it aids one in understanding the world".
} 
What I have called "value-centrism" is only one alternative to a reasonscentric approach to normativity. There is also "ought-centrism", "3 "rationality-centrism", ${ }^{4}$ deliberation-centrism, ${ }^{5}$ and "agency-or-action-centrism". ${ }^{6}$

Now Raz does not spend much time examining any of these competitor views head-on. He aims instead to persuade his reader that his particular reasonscentric view is correct by painting a picture of the interconnectedness of reasons, Reason, and rationality - a circle of concepts that arguably explains the intuitive domain of "the normative" - which he hopes the reader will find compelling. Raz tells his reader how he sees things-including what he thinks is wrong with opposing views - and hopes that the reader will look at things his way too. There is a limitation to such approaches, however. Arguably, they do not tackle issues where the rubber hits the road, that is, where conflict between two competing ways of understanding a phenomenon is not settled by appeal to pre-theoretical intuitions but requires an adjudicative argument that goes beyond the presentation of hard-to-compare attractive theories on each side. So perhaps Raz is a little quick in dismissing competitor views.

For example, Raz dispatches value-centrists by arguing that understanding normativity in terms of values must be mistaken since, unlike practical reasons, reasons to believe do not derive from the value of believing (42-44, 95). And since epistemic reasons are reasons, values are not the "key" to understanding normativity - both practical and theoretical. As he goes on to say, epistemic reasons are "adaptive" rather than "practical", the former marking "the appropriateness of an attitude in the agent independently of the value of having that attitude"(47) while the latter "are value-related" and "taken together, determine what and how, in light of the value of things, we should change or preserve in ourselves or the world" (47).

There are a variety of things a value-centrist might say here. She need not go along with Raz's assumption that epistemic reasons are normative in the same way as practical reasons. She might deny, as some do, that there is a unified notion of normativity that covers both reasons to act and reasons to believe. Or she might insist that although there is a single notion of normativity, epistemic reasons derive their normativity from truth while practical reasons derive their normativity from value, and that is no problem for understanding some of normativity in terms of values, namely the part that can be explained in terms of value. Or she might insist that epistemic reasons and practical reasons

\footnotetext{
${ }^{3}$ John Broome, Reasons, in Reason and Value: Themes from the Moral Philosophy of Joseph Raz 28-55 (R.J. Wallace et al. eds., 2004); John Broome, Rationality Through Reasoning (Forthcoming).

${ }^{4}$ Christine Korggaard, The Sources of Normativity (1996).

${ }^{5}$ Sharon Street, Coming to Terms with Contingency: Humean Constructivism about Practical Reason, in Constructivism in Practical Philosophy (J. Lenman \& Y. Shemmer eds., 2012).

${ }^{6}$ Christine Korsgaard, Self-Constitution: Agency, Identity, Integrity (2009); J. David Velleman, How We Get Along (2009); Michael Smith, Agents and Patients, or: What We Can Learn about Reasons for Action by Reflecting on our Choices in Process-of-Thought-Cases, 112 Proc. Aristotelian Soc. 309-31 (2012); Michael Smith, Lecture at St. Andrews Reasons Workshop (2013), http://www.st-andrews.ac.uk/ archproj/workshop/ session/?session=29.
} 
both derive their normative force from value-not the value of having true beliefs, in the case of beliefs, since as Raz rightly points out there is no value in believing truly that there are 2,345,678 blades of grass in the lawn, but the value of achieving understanding. ${ }^{7}$ So there is more to be said on behalf of the value-centrist than Raz's discussion would suggest. ${ }^{8}$

Note that the issue between "reason-centrists" and "value-centrists" does not concern the metaphysical or conceptual reduction of all normative concepts or properties respectively to "reasons" or to "values". What is at issue is not the merits of the "buckpassing" view of value according to which being valuable is nothing more than having reason-providing properties, ${ }^{9}$ but rather the substantive issue of which concepts lead us to the best explanation of nature of normativity.

Here I want to flag a way in which Raz's discussion of normativity represents a methodological advance over most other discussions of the topic. Instead of getting bogged down in the usual reductionist questions about normativity-eg "To what fundamental concept or property do all other normative concepts or properties reduce?", "Is normativity natural or non-natural?", "Is it

7 See Jonathan Kvanvig, The Value of Knowledge and the Pursuit of Understanding (2003); Catherine Elgin, Is Understanding Factive?, in Epistemic Value 322-30 (D. Pritchard, A. Miller \& A. Hadock eds., 2009) (science); Alison Hills, Moral Testimony and Moral Epistemology, 120 ETHICs 94-127 (2009) (morality), and many others.

${ }^{8}$ The only other view that Raz spends some time discussing is John Broome's ought-centrism (BRoome, supra note 3). Again, it seems to me that Raz's objections against Broome are a bit quick and draw much of their force from presupposing a Raz-friendly viewpoint. So, for example, Raz thinks that Broome's view of a pro tanto reason as something that figures in an explanation of why one ought to do something cannot account for cases of akrasia. But I did not see why this was so unless one already thought that a pro tanto reason was an inherently normative force, as Raz does (23). Broome can allow that a pro tanto reason on which one acts in cases of akrasia is a consideration that plays an against- $x$ role in an explanation of why one ought to $x$, that is, what one did not do. (Broome strictly defines pro tanto reasons in terms of "for- $x$ " roles, but it seems clear that he means to include against-x roles (BROOME, supra note 3 at 41 )).

Or, again, Raz thinks that Broome is mistaken in thinking that reasons can be defined in terms of explanations of what one ought to do because "oughts" are relative to an agent's options while "reasons" are not so relativized (22ff). But the linguistic intuition upon which Raz's argument relies seems to me plausible from a Raz-friendly perspective but readily rejectable pre-theoretically. If I return from the movie house, aflush with delight at Almodovar's quirkiness, I might well exclaim "You ought to go see this film!" without having formed any belief whatsoever, however implicit, about whether you were able or that you had conclusive reason to do so. And even if I believe you will never have the option of seeing the film, because all copies will be destroyed tomorrow, it still makes sense to say that you ought to see it as an expression of my belief about its value. "Ought" claims can be used in just the way Raz thinks "value" claims can be used-to say that you ought to $\mathrm{x}$ can mean "there's value in x-ing", without any presupposition that $\mathrm{x}$-ing is an option for the agent to whom the claim is addressed. The same goes for reasons-claims: they can be used to express belief in the value of $x$-ing without presupposing that the agent has $\mathrm{x}$-ing as an option. Indeed, none of the notions values, reasons, or ought seem essentially tied to a judgment about the options available to the agent on pain of conceptual incoherence. Note that if the availability of options does constraining work, it does so in helping to distinguish the direct second-personal form of "you" that is directed at a particular agent, from the generic sense of "you" equivalent to the generic "one"- as in "You, Mary Smith, ought to go to the film" vs. "One ought to go to the film", but this is a distinction that cuts across "reasons", "oughts", and "values". A full and careful examination of Raz's objections to Broome would take up the word limit of this review and so I do not undertake to do that here.

${ }_{9}$ Indeed, Raz's view, defended in Chapter 4, that reasons for action are reasons by being facts that establish that the action has some value, entails that buckpassing is false. See also Ulrike Heuer, Raz on Values and Reasons, in Reason and Value: Themes from the Moral Philosophy of Joseph Raz 129-52 (R.J. Wallace et al. eds., 2004) for a discussion of Raz's views about buckpassing. By implication, then, Raz's insistence on reasons and not values being the "key" to an explanation of normativity, then, crucially turns on his view that epistemic reasons are not derived from values. 
attitude-dependent or attitude-independent?"-Raz prescinds from reductionist metaphysics and trains his eye on the phenomenon of normativity as we experience it. Talk of a "key" to normativity is then talk of explanatory, but not metaphysically reductionist, key. Raz's non-reductionist approach has much to be said for it: let us understand a phenomenon more fully before rushing to reduce it. Non-reductionist theorizing about the normative might include questions such as, "what is it to be a reason or value?", "what sorts of considerations are reasons?", "what is practical reasoning", "what is rationality?", "what is the relation between epistemic and practical normativity?", "what is the relation between justification and explanation?", "what is the relation between reasons and values and ought and rationality?", "What does agency have to do with normativity?" and so on. In the next three sections, I outline and raise some worries about Raz's answers to three foundational questions about normativity: What are reasons? What is the faculty of reason? And what is rationality?

\section{Reasons}

Raz tells us that a reason is "part of a case for" believing, feeling, or intending to do something, and it is "inherently" normative, that is, intrinsically normative and not normative because of some role it plays in, for example, explaining why one ought to feel, believe, or do something. He goes on to say: "The primary significance of reasons for emotions, beliefs, actions, or whatever else, is to make certain responses eligible, appropriate" (5). Thus, reasons relate to our Being in the World by being what makes our responses to features of the world appropriate.

A reason is "part of a case" for something, and it is "inherently" normative. So far, so good; this is what we might call the "standard" externalist view about reasons shared by many others, ${ }^{10}$ including Derek Parfit, ${ }^{11}$ Thomas Scanlon (1998), ${ }^{12}$ Jonathan Dancy, ${ }^{13}$ and David Enoch. ${ }^{14}$ According to the standard view, a reason is a consideration that inherently "counts in favor" of feeling, believing, or acting/intending, where "counting in favor of" is a matter of being at least pro tanto justificatory in the performance of an action or in the having of an attitude.

Raz, however, departs from standard externalism by adding a further condition on what it is to be a reason: "To be a reason a fact must be one that

\footnotetext{
${ }^{10}$ Raz eschews labels such as "reasons externalism", but despite borderline skirmishes about how to apply the label, his view fits squarely among views that go under it. See his n. 23 (27).

${ }^{11}$ Derek Parfit, On What Matters, Vols. 1-2 (2011).

12 Thomas Scanlon, What We Owe to Each Other (1998).

${ }^{13}$ Jonathan Dancy, Practical Reality (2000).

14 David Enoch, Taking Morality Seriously (2011).
} 
we can respond to using our rational powers, whether or not on a specific occasion that is how we do respond to it" (87). Thus to be a reason, a consideration not only has to be inherently part of a case for something but also must be something we are capable of responding to by our "rational powers", that is, roughly, our capacities to recognize and respond to considerations that count in favor. (We will have a closer look at rational powers later.)

Now Raz says that this further condition derives from what he calls the "normative/explanatory nexus", the claim that "every normative reason can feature in an explanation of the action for which it is a reason, as a fact that, being recognized for what it is, motivated the agent to perform the action, so that the agent guided its performance in light of that fact" (28). That is, a normative reason must be able to explain action "because they are normative reasons, and by being normative reasons" (28). And later: "The nexus requires that reasons can explain agents' beliefs or actions or emotions in a special way: In their exercise of their rational powers, agents are led to awareness of the fact that are reasons qua reasons, and to rational reaction to this awareness" (35). Later Raz says that this further condition on reasons "basically repeats" the normative/explanatory nexus (87).

But standard externalists (and many internalists) accept the normative/explanatory nexus without accepting Raz's further condition on reasons. Should externalists accept Raz's further condition? Standard externalists make good on the nexus in the following way. They start by assuming (sometimes implicitly) a background constraint on reasons: they are considerations that count in favor of feeling, believing, or doing for creatures like us, where what it is to be a creature like us is naturalistically specified. Suppose the stove is $150 \mathrm{~F}$. Creatures naturalistically like us feel pain when we touch objects with temperatures of around $135 \mathrm{~F}$ or above. This fact is relevant to its being a normative fact that being 150 $\mathrm{F}$ is a reason not to touch it; if we were built differently, if say our pain threshold were $175 \mathrm{~F}$, then the fact that it is $150 \mathrm{~F}$ would not be a reason not to touch it.

This naturalistic constraint ensures that we will never have reasons to do things that count in favor only for Martians or beetles or amoeba, but we still need to account for the fact that, necessarily, normative reasons can explain action by guiding action through being recognized as reasons. How do standard externalists account for these guidance and recognition conditions? Most explain how a normative reason can guide an agent in acting by appealing to a different normative phenomenon, rationality. What it is to be a rational agent is to recognize and be guided by considerations that count in favor of doing, believing and feeling, for creatures naturalistically like us. Thus, a normative reason straightforwardly explains actions of rational agents by virtue of what it is to be rational.

What about the actions of less-than-rational agents? Here standard externalists can help themselves to a proposal Raz makes as to how a 
normative reason can explain the actions of a less-than-rational agent. He tells us that

reason-explanations explain action and belief by reference to their inherent features. After all, it is inherent in beliefs that those having them take them to be warranted, and would abandon them had they thought that they were unwarranted. Similarly, by their nature intentions to act involve belief in reasons for the intended action. Hence reason-explanations deepen our understanding of intentions, actions, and beliefs, by contributing to an understanding of whether they have the features that they purport to have (31).

So normative reasons figure in the explanation of less-than-rational action by way of figuring in the explanation of the agent's beliefs. He asks us to compare two explanations of action:

a) The agent did it because he believed that $R$

b) The agent did it because he mistakenly believed that $R$

(where ' $R$ ' has the required content for a reason-explanation) (31).

Raz says that "it would be a mistake to think that (b) is the same explanation as (a) because the reference to the fact that there was no $\mathrm{R}$ is explanatorily idle. Rather (b) is a more comprehensive explanation than (a). (a) is adequate to a certain range of interests in why the agent so acted. (b) is adequate for a wider, perhaps one may say here, deeper range of interests" (31). So R can explain a less-than-rational agent's action via her mistaken belief that R. Such an explanation appeals to a "deeper" range of interests, including, for example, whether the agent's belief on the basis of which she acted had the features she thought it did.

So a standard externalist can account for the normative/explanatory nexus by first, imposing a weak naturalistic background constraint on reasons and second, insisting that a different normative concept-rationality-is that by virtue of which necessarily reasons can explain both rational and less-thanrational actions in a way that meets the guidance and recognition conditions. This is a simple, attractive way of accounting for the nexus and one already implicit in many standard externalist views.

One reason to reject Raz's way of accounting for the nexus, then, is that it is otiose; the nexus can be accounted for in an attractive way without any need to appeal to his further condition on reasons. Another is that the standard way of accounting for the nexus is arguably preferable. For one thing, Raz's further condition appeals to "rational powers", but, as we will see, it is unclear and controversial what those are, and so Raz's further condition is unclear and controversial. For another thing, Raz builds his condition into what it is to be a reason, thus imposing on the notion of a reason an unnecessary normative condition that more naturally belongs not to our understanding of reasons but to our understanding of rationality. Instead of having to answer one normative 
question in order to determine whether something is a reason-Does it count in favor for creatures naturalistically built like us? - Raz must answer two: Does it count in favor (for creatures naturalistically built like us)? And, is it something we are capable of responding to by our rational powers? There is no need to burden the notion of a reason in this way in order to account for the nexus.

It might be wondered whether Raz's account of reasons is properly understood as a genuine departure from rather than a mere notational variant of standard externalist accounts. Perhaps by "rational powers" Raz means what standard externalists mean by (substantive) "rationality", namely, whatever capacities are required for creatures naturalistically like us to recognize and respond to reasons, ie, what constitutes our "rationality" in the standard externalist's sense. In that case, so long as we were to reject Raz's claim that his "further condition" is built into what it is to be a reason, his account would just turn out to be a form of standard externalism, and the further condition would be much ado about nothing.

There is an interpretive issue here, but I do not believe that Raz aims to be presenting an already-familiar view of reasons. Part of the interpretative difficulty comes from Raz's ambiguous use of the term "reasons". As we have already seen, Raz explicitly says that "to be a reason a fact must be one that we can respond to using our rational powers" (87). But he also says that "Reason, i.e., [our] rational powers or capacities" (93), is "the general reflective capacity to recognize reasons" (90). So he appears to be claiming both that it is in the nature of a reason to be recognized by Reason, and that it is in the nature of Reason to recognize reasons - a circularity that is not of the happy kind. ${ }^{15}$ What these passages suggest is that Raz has two notions of a reason in mind-one, the standard externalist notion, namely, a consideration counting in favor, which he employs when he says that we recognize and respond to "reasons" by exercising our rational powers, and another, more robust, sense which he employs when he says that a "reason"-in the standard externalist sense- has to be recognizable by our rational powers in order to be a "reason"-in his more robust sense. Most importantly, as we will see, Raz has something substantive in mind when he talks of our "rational powers", and so his appeal to rational powers is not the standard externalist's appeal to a notion of "rationality" - as the capacities, whatever they might be, required to recognize and respond to considerations that count in favor. The correct interpretation of Raz, I think, is that rational powers are part of Reason, which is the general capacity to recognize considerations that count in favor, while reasons are considerations that count in favor that can be recognized by our rational powers. In short, either Raz should be understood as presenting a standard, familiar externalist view of reasons, or he should be understood as offering a

\footnotetext{
${ }^{15}$ Raz aims to be offering analyses of reasons and Reason, not simply describing how the concepts relate.
} 
genuine and interesting modification of such views. I believe the latter interpretation is correct. But if it is, as we have seen, we have reason to reject his account in favor of the standard one.

So far I have ignored the details of Raz's interpretation of the further condition - and therefore of the nexus. What counts as a "rational power" is obviously one, but we will be returning to that later. Here I want to raise some questions about what Raz calls the "knowability requirement" (87), which is a condition of the nexus: "only features of the world that we can in principle come to know can constitute reasons" (87). He also sometimes talks about this requirement in terms of the agent's ability to "recognize" reasons. Standard externalists sometimes use "recognize" as a general, catch-all term that is meant to be neutral between different ways in which one can become psychologically acquainted with an item, where "acquaintance" has a direction of fit from the world to the acquaintance. Indeed, I have used "recognize" in just this way in discussing the way in which standard externalists can account for the normative/explanatory nexus. But Raz's knowability requirement appears to be stronger.

Raz does not give a defense of knowability as the right psychological connection between a reason and an agent, nor does he tell us what he takes knowability to involve, but if we take "knowability" at face value, I suspect that the condition is too strong. The fact that an earthquake is about to devastate southern California can be a normative reason for you to avoid travelling there although you cannot know the fact that is the reason. But you might have some other psychological connection with it-a hunch or premonition, for example. Or take string theory. You cannot know whether string theory gives the correct theory of everything (because it is just too complicated, say), but a justified true belief based on the conjectures of some of the leading contemporary physicists may be all the psychological connection required for the conjectures to be a normative reason for you to believe the theory. Or take Williamson's ${ }^{16}$ anti-luminosity arguments. If those arguments are correct, then although I cannot know in certain cases that I am in pain, the fact that I am seems to be a normative reason for me to get out of that state. Insofar as Raz means something stronger than the "psychological acquaintability" (with the appropriate direction of fit), his understanding of the nexus is arguably too restrictive.

There is another aspect of the knowability requirement that seems worrisome. Raz insists that "the nexus is interpreted to apply to each individual agent and reason, that is, it is understood to imply that the reasons an agent has on an occasion are reasons that, given an appropriate understanding of 'can', can explain his action on that occasion" (34). This suggests that what counts for a reason for you is itself relativized to features of your psychology-

\footnotetext{
${ }^{16}$ Timothy Williamson, Knowledge and its Limits (2000).
} 
what you can know-in circumstances of this kind (126). Most externalists make the condition of psychological acquaintability relative to a broader type-for example, "naturalistically undefective human". It is because Hitler could as a token of this type come to be psychologically acquainted with the fact that the humanity of Jews is a reason not to commit genocide against them that he has a normative reason not to do so. This normative reason figures in an explanation "answering to broader interests" as to why he (wrongly) committed genocide against them, even though, by hypothesis, Hitler could not have come to know this reason as a reason not to commit genocide. Raz does point out that one can be in a position to know even if one does not actually know in a given case (34), but the "can" here again seems to be restricted to one's individual psychological capacities, and we can imagine Hitler without the requisite ability. The intuitively correct extension of our normative reasons seems to ask for relativization to something broader than the individual's psychological capabilities. There is a balance here between getting the intuitively right extension of our normative reasons, on the one hand, and being able to account for the nexus, on the other. It seems doubtful that knowability relativized to an individual's peculiar psychology achieves the correct balance; it will give us far fewer normative reasons than we actually have.

I have suggested that there are grounds for resisting Raz's departure from familiar forms of externalism about reasons. But there is much in his account that, it seems to me, should be wholly accepted. For instance, anyone-whether externalist or not-who thinks that an agent must in principle be able to "recognize" a reason as a reason, need not be troubled by the challenge that such a condition requires agents - even children - to have the highfalutin concept of a reason. As Raz explains, "having a concept" has stronger and weaker readings, and the nexus need only take the weaker reading according to which one has the concept of a reason so long as "one follows the standards for its correct use even if one does not know what they are" (32). And Raz's defense of the core idea of the nexus - that reasons themselves and not our beliefs about them explain our actions - provides perhaps one of the most persuasive attacks on the Davidsonian belief-desire model of intentional action explanation.

\section{Reason}

Raz tells us that "Reason" is the "general reflective capacity to recognize reasons" (90). It includes our rational powers, which in turn include our ability to reason, but so much more besides-for example, automatic processes and our powers of memory and concentration (90-91). It includes all the mental capacities we have that enable us to recognize considerations that count in favor of something. It is thus the general capacity we exercise in bringing about features it is appropriate to bring about given other features of the world. Reason is the central capacity we exercise in Being in the World. 
At the heart of Reason, however, are our rational powers. Our rational powers are the capacities we use to recognize considerations that count in favor. And as we have seen, Raz thinks that our rational powers are a normative constraint on what counts as a reason. Understanding our rational powers, then, is crucial to understanding both reasons and Reason. So we need to ask, which are our rational powers?

Given their central role in his account of both reasons and Reason-and as we will see later, rationality -it is somewhat surprising when Raz says that he "will say little on the subject" (90). Instead, he suggests various ways of determining which capacities are among our rational powers. He writes:

Various connections between Reason and other concepts can be called upon in clarifying the concept [of our rational powers]. One is between Reason and personhood: creatures that do not have rational powers are not persons. A second is between Reason and accountability, which marks one sense of responsibility. Creatures that do not have rational powers are not responsible (accountable) for their actions. And a third is with the notion of irrationality. It [leads] to the irrationality test... (91).

These various ways of determining which capacities are among our rational powers are meant to give us a unified picture of the kinds of capacities Raz has in mind. But it is unclear whether the suggested routes to clarification lead to a unified view of our rational powers. ${ }^{17}$

Consider the "irrationality test". This test "says that if the exercise of a capacity can be nonderivatively irrational (that is irrational not because something else is irrational) then the capacity is one of our rational powers" (88). According to this test, included among our rational powers are not only our ability to reason but also our ability to form intentions and decisions (88). This is because we can form non-derivatively irrational intentions to, say, have chocolate cake against our better judgment without demonstrating any failure in reasoning. Therefore, the forming of intentions passes the irrationality test. Similarly, the test includes among our rational powers the capacity to have some emotions such as "empathy" (92) "because some emotions can be nonderivatively irrational" (91) if, for example, "they are disproportionate reactions to rational beliefs" (92). But it rules out memory and concentration as among our rational powers "because failure of memory and concentration, however bad, are not irrational" (91).

Consider now the personhood "test": rational powers are capacities that persons necessarily have. An ability to empathize is a rational power according to the irrationality test, but it does not seem to qualify as a rational power

\footnotetext{
${ }^{17}$ It might be thought that the different extensions provided by the different ways of elucidating the notion of rational powers is just a matter of disagreement about borderline cases. But Raz firmly notes that these three ways of elucidating the concept of a rational power pertain to determining our "core" rational powers, not borderline cases of such powers (90-91). In any case, whether a capacity to empathize is or is not a core rational power is significant for how we understand reasons, Reason, and rationality. I discuss only the personhood and irrationality "tests" because I found the responsibility "test" difficult to interpret.
} 
under the personhood test, at least if we employ an ordinary, intuitive notion of a "person". You can be a person without having the ability to empathizenarcissists are persons and so are sociopaths. Presumably, the same would go for an ability to appreciate humor-it passes the irrationality test but not the personhood test. Our humorless colleagues are people after all. On the other hand, there are powers that seem to pass the personhood test but not the irrationality test. For instance, to be a person you, arguably, have to have a reasonably-functioning memory. Alzheimer's patients with very severe memory degradation seem to reach a point where they are no longer persons. But memory - in any degree - is not something that can be exercised rationally or irrationally on its own account. The same goes for the ability to concentrate. A person needs to have the ability to concentrate on a task. But concentration is not a capacity that can be non-derivatively rationally or irrationally exercised.

So these two ways of demarcating our rational powers arguably lead to different sets of core rational powers. This unclarity about our core rational powers matters because, according to Raz, these powers help to determine which reasons we have and whether we have a defect in Reason (and, as we will see shortly, whether we are rational). Someone may have no reason to stop beating her spouse and may be exercising her Reason perfectly well if her rational powers do not include an ability to empathize, a la the personhood test, but may be defective in Reason and have a reason to stop harming her, a la the irrationality test. The plausibility of Raz's theory of normativity turns, in part, on substantive upshots like these, and we do not yet have a clear idea of what those substantive upshots are without a clearer understanding of our rational powers.

We might suggest a different test for determining our rational powers, one which does not rely on large, controversial concepts like "irrationality" or "personhood" (or "responsibility"), but instead draws on a distinction between capacities that are "directly" exercised in recognizing reasons-call those "rational powers" - and those that are "indirectly" exercised in recognizing reasons-not among our rational powers. ${ }^{18}$ So memory, concentration, a capacity to enjoy humor or to empathize are all indirectly exercised in recognizing that one has reasons to pursue enjoyments, laugh at jokes, stop hurting others, etc. and thus are not among our rational powers, while the ability to become psychologically acquainted in the right way with reasons, whatever that involves, is a rational power. An ability to empathize would properly be a borderline case by this test. This distinction between "direct" and "indirect" contributions to recognizing reasons is messy to be sure, but it might be filled out once a theory of how we come to recognize reasons is developed.

\footnotetext{
${ }^{18}$ Raz makes a similar distinction when he says, perhaps implicitly recognizing the oddity of saying that memory and concentration are not among the powers we employ in recognizing reasons, that perhaps memory and concentration are "ancillary" to our rational powers, "enabling them to function well" (91).
} 
It is worth pointing out that Raz thinks that "an explanation of the productive process that leads to awareness of the reason and from there to the motivation and the action" of the kind that would be required in the alternative above is "not needed for an understanding of the normative/explanatory nexus" (33). I suspect he thinks this because he is satisfied with a very general explanation of intentional action that does not yet account for which capacities are exercised when we recognize reasons (33). Once we focus on the question of which capacities are among our rational powers, an explanation of how we get from the exercise of those powers to the recognition of and response to reasons seems to be highly significant for answering the question of which capacities are included.

We might also question Raz's application of the irrationality test. Is empathy intrinsically rational or irrational? Bernard Williams ${ }^{19}$ labeled people who lack empathy as cruel, despicable, and unkind, but insisted there was no flaw in their rationality - that is, they were not failing to recognize any reasons they had. Raz is of course right that empathy is intrinsically rational or irrationalthat, for instance, it makes sense to speak of a robustly "disproportionate" reaction to rational beliefs - if one assumes an externalist view of reasons as Raz does, and means by "rationality" what Raz means by it, namely, the wellfunctioning of the abilities required to recognize considerations that count in favor, for it is plausible that the spouse-batterer will need a capacity for empathy to recognize that her suffering is a reason for her to stop beating her. But if you have a different view of rationality, or are not an externalist about reasons, you would not think that some of the capacities that Raz thinks pass the irrationality test do so.

Let me end my discussion of Raz's view of Reason with a broader, speculative worry that has application to all externalist accounts. According to externalists like Raz, considerations that count in favor are inherently normative, and Reason is the general reflective capacity to recognize and respond to such considerations. Thus, Reason is the set of capacities aimed at discovering what counts in favor of what and what is the appropriate response to that discovery. Since what counts in favor and the appropriateness of responding to recognition of what counts in favor are both given to us by the way the world is, we are left with an essentially passive view of Reason.

Raz's view of Reason has us Being in the World by sitting back, letting the world tell us not only what counts in favor of what, but also what we should do in response to it. The exercise of Reason is akin to the execution of a computer program: rational agents are like automata with a script to follow provided by the way the world is. Is this really all there is to being an agent of Reason?

\footnotetext{
${ }^{19}$ Bernard Williams, Internal and External Reasons, in his Moral LucK (1981).
} 
Raz thinks that his view is not "unduly passive" since Reason includes capacities not only to recognize reasons but also to respond to them (92). ${ }^{20}$ The fact that Reason includes capacities to respond to reasons, however, while preventing Reason from being nothing more than "just tabling reports, as it were, of what reasons are to be found where" (92), does not address the worry raised here. Since the appropriateness of our responses to reasons are "out there", to be discovered, our Being in the World remains scripted by the world.

For rational agency to be genuinely active, the will (or willing), broadly understood as agency itself, must play a role in determining the appropriateness of our responses to reasons. ${ }^{21}$ This brings us to a deep division between externalists, on the one hand, and "voluntarists", those who think that the will or willing can be that in virtue of which something is a reason, on the other.

Externalists are happy to understand rational agency in an essentially passive way: what we do as rational agents is discover reasons and then respond to them appropriately, where the appropriateness of our response is itself given to us by the way the world is. Externalists think that the role of the will in practical reason is primarily two-fold: to bring us from a conclusion about what we have most reason to do to an intention to do it (or from the intention to the doing) - cases of akrasia are paradigmatic instances in which the will fails in this regard-and to be a condition that affects the "application, strength or stringency" of a reason, as when you have a reason to get exercise by going for a walk in the park as opposed to a reason to get on a treadmill because only the former engages your will (183). Willing something - as in a promise to do something - can be a condition for application of a reason to do that thing that depends on the willing.

Voluntarists, in contrast, give the will a more fundamental, active role in the determination of our reasons. The will can be that in virtue of which some consideration is a reason, that is, it can be the "source" of a reason's normativity. By willing something (under suitable constraints), you can make it the case that something is a reason. This is one of the great, provocative ideas behind broadly Kantian-inspired approaches to normativity. Thus, while externalists think that the normative dimension of our Being in the World is fundamentally passive, voluntarists think that it is fundamentally active; the will is what makes something a reason, or valuable, or rational, or what one ought to do. So perhaps the critical issue in whether to accept an externalist account of reasons is not the usual reductionist one-can it be reconciled with a

\footnotetext{
${ }^{20}$ Raz interestingly suggests that "recognizing reasons involves responding to them" (93). This is perhaps most plausible in the case of theoretical reasons since recognizing sufficient evidence for $\mathrm{p}$ arguably amounts to believing that $\mathrm{p}$ - though this is highly controversial — but Raz even more controversially thinks that the interdependence of response and recognition also holds for practical reasons (93).

${ }^{21}$ Raz has much to say about what role the will plays when there are multiple, "eligible" responses, and I have suggested elsewhere that this role is essentially passive. See Ruth Chang, Are Hard Choices Cases of Incomparability? 22 Philos. Issues 106-26 (2012).
} 
naturalistic metaphysics and epistemology? - but rather one having to do with the nature of ordinary phenomena like normativity and agency-does it give agency the right role in normativity? Perhaps what is wrong with Raz's view of Reason-and externalist views of reasons more generally - is that they leave us with too passive a view of rational agency. Making good on this idea, however, requires detailed argument that cannot be undertaken here. ${ }^{22}$

\section{Rationality}

The final component of Raz's view of normativity is his widely-known account of rationality. ${ }^{23}$ Being rational is a matter of "being properly guided by well-functioning rational powers" (93). Rationality governs processes or movements between states of mind, and thus Raz's view of rationality is "dynamic" rather than "static" (94). According to the dynamic view, we can be rational while holding contradictory beliefs, since rationality does not govern the relations between the contents of our mental states $(94,96,162)$. Moreover, we can be rational while failing to conform to our reasons, since we can fail to conform due to bad memory, mistakes, or ignorance-and these are not failures in the exercise of our rational powers and so do not make us irrational (93, 162). Finally, rationality "is not a capacity we use at will" (159). Raz likens the engagement of our rational powers to the engagement of our perceptual capacities, such as seeing and hearing (95). We do not have to exert our wills to hear the noises around us - so long as we are conscious and functioning normally, our hearing capacities are at work, allowing us to hear the sounds around us. Similarly, so long as we are conscious and functioning normally, our rational powers are engaged, allowing us to recognize the reasons that we have (95). In short, we are rational if it is business as usual.

Now we raise a question. What reason is there is to be rational? If rationality is as Raz says, the question "What reason is there to be rational?" amounts to the question, "What reason is there for our rational powers to be functioning well?" Raz's answer is unequivocal: "we need no reasons to function rationally, just as we need no reason to hear sounds in our vicinity" (95). But this is not to say that there's no point to being rational: "The point is obvious: [being rational] is a way of identifying and responding to reasons" (96). If you ask, however, what reason there is to conform to this way of identifying and responding to reasons, there is no answer. You just are.

The problem that Raz is trying to address, though he does not put it this way, is the regress problem, the problem of having to appeal to never-ending

\footnotetext{
${ }^{22}$ For some steps in this direction, see eg Ruth Chang, Voluntarist Reasons and the Sources of Normativity, in REASONS For ACTION 243-71 (D. Sobel \& S. Wall eds., 2009).

${ }^{23}$ Michael Bratman holds a similar view. See Michael Bratman, Agency, Time, and Sociality, 84 Proc. Addresses Am. Philos. Assoc. 7-26 (2010).
} 
resources to justify being rational, that is, carrying on, business as usual. What justifies engaging in this way of identifying and responding to reasons? ${ }^{24}$ If one appeals to some consideration, like "it's good to identify and respond to reasons in this way" or "you get what you want if you operate business as usual", the question rears its head again: Why should you do what it's good to do/what gets you what you want? To avoid the regress, Raz, like others, "goes constitutive". Instead of appealing to a further consideration that justifies the activity of identifying and responding to reasons in this way, Raz holds that "rationality, namely responsivieness to reasons, is...constitutive of being a person" (97-99). So if you are a person, it makes no sense to ask for reasons to do and be what constitutes your personhood. And since we cannot avoid being persons, it seems that the regress is stopped.

Unlike other constitutivists, Raz offers a "formal" constitutivist account, eschewing reliance on conceptions of "substantive" or evaluative notions, such as what it is to be a good agent, a la Christine Korsgaard (2009). ${ }^{25}$ His formal account consists in two claims about what is constitutive of being a person: (i) "responsiveness to epistemic reasons is constitutive of believing" (97), and "we are persons so long as we have rational capacities, and by and large our beliefs and actions are governed by them, which is the same as saying so long as we have beliefs" (98); and (ii) "responsiveness to practical reasons is also constitutive of being a person, for without it there is no action with the intention of doing it" (98). In other words, being a person is constituted by being responsive to our epistemic and practical reasons. The arguments Raz gives in support of this view of personhood are sketchy and suggestive, occurring over a few pages (96-99). The main idea is that it purportedly follows from a proper understanding of the concepts "person", "belief", "reasons", and "action for a purpose", that being a person is constituted by responsiveness to reasons. I won't be discussing his arguments here, though there is much of interest to discuss. Instead, I want to suggest that even if Raz is right that being a person constitutively requires responsiveness to reasons, the regress problem remains.

The regress is supposedly blocked because we cannot help but be persons. Since we cannot help but be as we are, and how we are is constituted by responsiveness to reasons, we cannot help but be responsive to reasons. From this, Raz thinks it follows that there is no cogent normative question, "What reason is there to be rational?" but only a non-normative question "[W] hat is the hold reasons have on us?" (99). He says: "The answer [is] that we cannot ignore them because we are persons, or more precisely, because rational powers are constitutive of personhood, and because they are powers whose use does not depend on our will" (99).

\footnotetext{
${ }^{24}$ See Peter Railton, How to Engage Reason: The Problem of Regress, in Reason and Value: Themes from the Moral Philosophy of Joseph Raz 176-201 (R.J. Wallace et al. eds., 2004) for a discussion of the regress problem in the context of practical and theoretical reason.

25 Christine Korsgaard, Self-Constitution: Agency, Identity, Integrity (2009).
} 
But I doubt that this strategy works. For one thing, it does not follow that there can be no normative question, "What reason is there to be rational?" just because some non-normative state- the state of responding to reasons-is inescapable and not a matter of our will. Suppose you were born with only three limbs. You cannot escape the fact that you were born with only three limbs, and whether you were so born does not depend on your will, but you can still cogently ask, "What reason is there for me to be in this state?" There is no conceptual incoherence in your asking what reason there is to be in a state you must necessarily and cannot choose whether to be in. Similarly, there is no conceptual incoherence in your asking what reason there is to be in a state of responding to reasons you must necessarily be in and over which you do not exercise choice or agency. The regress problem is a problem of justification, and even if you cannot help but have the rational capacities you have, it can make sense to ask for justification for having those capacities. ${ }^{26}$

Of course, being born with only three limbs is non-essential to you. Compare being a Homo sapien; perhaps being of that species is essential to your nature. If so, it seems that you would not be in a position to ask, "What reason is there to be a Homo sapien?" and so the normative question would be closed to you. If personhood were like that, Raz may be able to stop the regress for all such creatures.

Raz does not, however, argue that being a person is essential to or constitutive of us. Indeed, he sometimes seems to regard personhood as an honorific, a state some creatures achieve by having rational powers. In any case, it might be doubted whether personhood-an ability to recognize and respond to reasons - is essential to creatures like us. Here is a thought experiment. Many of our beliefs, feelings, and actions are the result of automatic processes-we automatically believe that we occupy space, we automatically feel embarrassed when we make a silly mistake in public, and we automatically put one foot in front of the other when walking from one point to another-arguably without any mediation by other mental states. ${ }^{27}$ Now imagine that all of our beliefs and actions were the result of automatic processes. Instead of having beliefs, feelings, and actions mediated by recognition of reasons as reasons and then being guided by reasons via our recognition, our recognition of and responses to reasons are, as it were, hard-wired in us. Since we have no need for an ability to recognize and response to reasons via our rational powers, we have no such ability. Would we still be the creatures we essentially are? Arguably, yes. Personhood, understood as necessarily involving the exercise of rational powers, does not seem to be part

\footnotetext{
${ }^{26}$ See also David Enoch, Agency, Schmagency: Why Normativity won't Come from What is Constitutive of Action, 115 Philos. Rev. 169-98 (2006); David Enoch, Schmagency Revisited, in New Waves in Metaethics $208-33$ (M. Brady ed., 2011).

${ }^{27}$ See Peter Railton, How to Engage Reason: The Problem of Regress, in Reason and Value: Themes from the Moral Philosophy of Joseph Raz 176-201 (R.J. Wallace et al. eds., 2004) for a discussion of the ubiquity of automatic processes.
} 
of our natures. Indeed, exercising rational powers is hard, time-consuming work. If we could recognize and respond to reasons automatically, without any need to flex our rational powers, just think of all the novels we could read.

We need not rely on such fanciful thought experiments, however. Even if having the ability to recognize and respond to reasons is essential to who we are, this does not block the question, "What reason is there to be rational?" This is because what is essential to our being, if anything is, is our capacity or power to recognize and respond to reasons, not our actually doing so. But being rational is not simply a matter of possessing certain capacities-it involves exercising them; rationality is the well-functioning of these capacities. So even if we could not be the creatures that we are without having this capacity, that does not prevent us from asking what reason we have to exercise that capacity. True, we cannot help but have the capacity, but it is perfectly coherent to ask what reason we have to be rational, that is to exercise it.

There is another way to make this last point. To avoid the regress, Raz's view of rationality must deny that there is any value to being an agent who recognizes and responds to reasons, above and beyond the value of the ends the agent has and her successful achievement of them. But it seems clear that there is some value in being the kind of creature who recognizes and responds to her reasons.

Here is another thought experiment. Suppose you are behind a veil of ignorance and are asked to choose between being one of two kinds of human, one that is rational, that is, has the well-functioning capacities to recognize and respond appropriately to its reasons, and one that is not rational, that is, that does not have these well-functioning capacities. You do not know what the ends of each human are. Nonetheless, it seems clear that there is something to be said in favor of choosing to be the creature that has the well-functioning capacities to recognize and respond appropriately to its reasons. This is so regardless of the value of the ends that creature has. If this seems plausible, it suggests that there is value to being rational apart from the value of the ends for which one has reasons. If there is value to being rational, it makes sense to ask, what reason is there to be rational? And the regress remains.

This thought experiment also shows that the applicability of the question "What reason is there to $x$ ?" does not require $\mathrm{x}$-ing to be a matter of actual willinghypothetical willing can do the job. So long as there is value in $\mathrm{x}$-ing, it makes sense to ask for reasons to $\mathrm{x}$, and we can show that this is so by jimmying up a case-typically one where our essential selves are to choose what non-essential features to have-in which the question of what reason there is to $\mathrm{x}$ makes sense.

\section{Source}

I'll end with some doubts about what is probably the deepest claim Raz makes about normativity. Raz believes that the idea of normativity's "source" is incoherent. 
The question of normativity's "source" is a question that stands outside the conceptual web of normative concepts and asks, what grounds all of that? In virtue of what is all that is normative normative? Crucially, it is a prima facie metaphysical, and not normative, question.

Raz says "if we go outside and examine normativity as a whole", we "lose the ability to explain it" (99). The explanation of normativity is "inevitably internal - reasons are what we should follow, disregarding them is unjustified, etc. We can explain from the outside the inescapability of normativity, the hold reasons have on us..." (99) but it makes no sense to try to explain what grounds all of normativity from outside the web of normative concepts.

This seems to me mistaken. Many philosophers (myself included) have asked the question, "In virtue of what is something a reason?" and have provided various answers. Raz may have substantive disagreements with these philosophers about the usefulness of their explanations, but these philosophers cannot rightly be accused of being incoherent.

The "in virtue of what?" question is a standard question in metaphysical inquiry and can, in principle, be asked of any fact or proposition. ${ }^{28}$ In virtue of what is this liquid water? In virtue of what a mental state a belief or knowledge? In virtue of what is an event a cause? In virtue of what is a generalization a law? And so on. It would be good to know what Raz thinks is so special about normativity such that this familiar metaphysical question is incoherent when asked about normativity.

Now there are different "grounding relations", different ways to interpret the "in virtue of what" question. One relation of relevance to theorists of normativity is that of constitution. ${ }^{29}$ When we ask, "In virtue of what is the fact that it's $150 \mathrm{~F}$ a reason not to touch it?" we might be asking, "What constitutes the fact that it's being $150 \mathrm{~F}$ is a reason not to touch it?" More generally, when we ask for the "source" of normativity, we might be asking for what grounds or constitutes something's being a reason. There are a variety of answers. Humean "internalists" answer by way of appeal to an agent's desires or dispositions; neo-Kantian voluntarists answer by appealing to an agent's will or act of willing; and standard externalists demur, saying that the question does not arise on their view.

Why does Raz so strongly insist that the source question is incoherent when asked of normativity? Here is a possible diagnosis: from the point of view of an externalist theory, the question is misguided since it asks for explanation where there is no more explanation to be had. Externalist explanations of why something is a reason, recall, bottom out with "It's just is a normative fact that such-and-such is a reason". Given that externalists deny that normativity has

\footnotetext{
${ }^{28}$ Kit Fine, The Question of Realism, 1 Philosopher's Imprint 1-30 (2001).

${ }^{29}$ See Ruth Chang, Grounding Practical Normativity: Going Hybrid, 164 PHILos. STud. $163-87$ (2013) for distinctions between the different grounding relations of interest to normative theorists.
} 
a source, it is easy for the externalist to slide, in a fit of overenthusiasm, to the stronger claim that it is incoherent to ask for normativity's source. But we must remember that reasons externalism is a substantive position that could be mistaken. It is one thing to say that, according to one's favorite theory, normativity has no source but quite another to say that the question of source is incoherent. As an externalist, Raz should simply demur instead of insisting that his substantive position is a conceptual truth. By insisting that the idea of the source of normativity is incoherent, he mistakenly dismisses in one fell swoop a burgeoning field of inquiry into the nature of normativity. 